\title{
Percepção e Linguagem: descrição de figuras ambíguas por alunos universitários da área biológica
}

\section{Perception and Language: description of ambiguous figures by undergraduate biology students}

\section{Sérgio Roclaw Basbaum*}

Pontifícia Universidade Católica, PUC-SP, São Paulo, São Paulo, Brasil

\section{Rafael Peres dos Santos**}

Universidade Estadual Paulista, UNESP, São Paulo, São Paulo, Brasil

\author{
Rafael Fernandes Barros*** \\ Universidade Estadual Paulista, UNESP, São Paulo, São Paulo, Brasil
}

\section{Lujani Aparecida Camilo****}

Universidade Estadual Paulista, UNESP, São Paulo, São Paulo, Brasil

\author{
Alfredo Pereira Júnior***** \\ Universidade Estadual Paulista, UNESP, São Paulo, São Paulo, Brasil
}

\begin{abstract}
RESUMO
Partindo-se de uma concepção merleau-pontyana do ato perceptivo e sua mediação pela linguagem, procedemos a um experimento cognitivo, tendo como objetivo verificar como a percepção de figuras ambíguas expressa-se em termos da linguagem verbal, por parte de graduandos da área biológica. Duas destas figuras mesclam formas biológicas e artefatos culturais, enquanto a terceira mescla duas formas de vida. Solicitou-se a um grupo de 120 alunos da Universidade Estadual Paulista (UNESP) que descrevessem, por escrito, as suas percepções em torno de três figuras. Fazendo-se uma análise das categorias que se destacaram nas descrições, e também uma reconstrução dos discursos por meio da técnica qualitativa do Discurso do Sujeito Coletivo, evidenciamos a riqueza do ato perceptivo, e de seus condicionantes culturais, os quais se expressam na linguagem.
\end{abstract}

Palavras-chave: Percepção, Linguagem, Significado, Ambiguidade.

\begin{abstract}
Departing from a Merleau-Pontyan concept of linguistic mediation of perception, we ran a cognitive experiment, having the goal of studying how the perception of ambiguous figures is expressed in verbal language. Two of the figures mix biological and technological forms, while the third mixes two biological forms. We asked a group of 120 undergraduate Biology students from State University of São Paulo (UNESP) to write about their perception of three ambiguous figures. We made an analysis of descriptive categories that appeared in the responses and used a qualitative method (Discourse of
\end{abstract}


the Collective Subject) to reconstruct the main features of the linguistic expression of preceptual processes. In conclusion, we found in these processes a richness of meanings related to cultural factors.

Keywords: Perception, Language, Meaning, Ambiguity.

\section{I ntrodução}

Certamente não negamos a originalidade da ordem do conhecimento em relação à ordem do percebido. Tentamos apenas desfazer o tecido intencional que liga uma à outra, reencontrar os caminhos da sublimação que conserva e transforma o mundo percebido no mundo falado, e isto é apenas possível se descrevemos a operação da fala como uma retomada, uma reconquista da tese do mundo, análoga em sua ordem à percepção e diferente dela. (MERLEAUPONTY, 2002, p. 156-157).

O presente artigo aborda as relações entre o domínio da percepção segundo Merleau-Ponty, a dimensão fundante das relações entre homem e mundo - e aquele da linguagem, especialmente a linguagem verbal, dimensão da costura coletiva essencialmente humana. De fato, se é razoável admitir que, sem a capacidade de perceber a si próprio e à sua circunstância, o indivíduo não pode dispor um mundo, é também lícito constatar que sem a linguagem este mundo não é passível de comunicação com outro indivíduo humano. Tais distinções ajudam a pensar a verdadeira alquimia cognitiva operada pelo corpo, que transforma o mundo percebido num mundo linguístico, com todas as consequências que, como se sabe, a capacidade linguística teve na evolução cognitiva e cultural da espécie humana.

Neste trabalho, procuramos pensar o problema distinguindo aspectos da percepção, do gesto e da linguagem, no âmbito de uma noção de produção mundo e de sentido. Tais distinções foram, em seguida, traduzidas para um exercício empírico, no qual estudantes universitários foram solicitados a descrever verbalmente figuras ambíguas, de tal modo a, em alguma medida, evidenciar relações entre o percebido e sua expressão em linguagem. Realizamos análise dos resultados em termos de uma distribuição em categorias interpretativas, e utilizando a metodologia do Discurso do Sujeito Coletivo (LEFRĖVE; LEFRÈVE, 2005).

\section{A Percepção Segundo Merleau-Ponty}

As considerações que se seguem têm origem numa matriz fortemente interdisciplinar, em que o legado do fenomenólogo francês Maurice Merleau-Ponty (que examinou amplamente a questão da percepção a 
partir da década de 1940) é posto em diálogo com outros autores, sobretudo da antropologia e da biologia. Ao buscar, no estilo da fenomenologia merleau-pontyana, uma compreensão da experiência perceptiva, consideramos que aquele que percebe e conhece não é apenas um cérebro, mas um indivíduo (ENGEL; KÖNIG, 1998). Para abordar a experiência perceptiva nestes termos, pode-se retomar 0 legado da escola Gestaltista e lembrar que percebemos sempre relações. Ilusões clássicas como a de Zollner (Figura 1 ) não deixam dúvidas de que, ainda que se possua uma certeza racional sobre a disposição paralela das retas, as relações de convergência e divergência que constituem o conjunto se impõem na experiência:

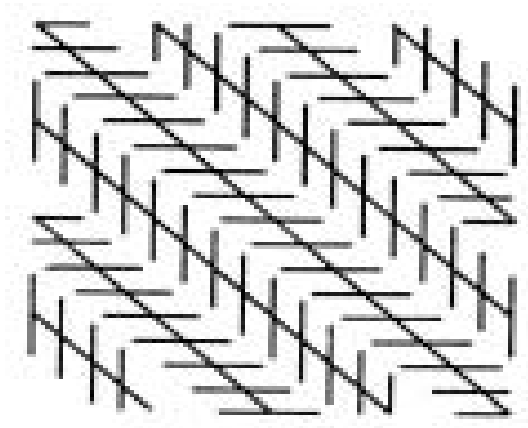

Figura 1: Ilusão de Zollner

O mundo percebido é, assim, um mundo pré-objetivo, anterior às operações da razão, em que a percepção atua de modo ativo, buscando apreender formas que permitam ao individuo situar-se de modo satisfatório na sua circunstância. Outros exemplos consagrados, como o do gato atrás de uma cerca - quando temos objetivamente, "partes de gato", mas percebemos "um gato" -, bem como a constatação de que possuímos um ponto cego na retina, sem que isso implique na presença de um ponto negro ou vazio em nosso campo visual (MATURANA; VARELA, 1995), permitem que se descreva contemporaneamente a percepção como "enativa" (NOE, 2004): a percepção encena um mundo, um horizonte de "coisas" que a razão poderá posteriormente tematizar como seus "objetos" (BASBAUM, 2006).

Diremos assim que, operando numa tensão permanente entre imanência e transcendência - já que percebemos sempre mais do que os estímulos dados, isto é: mais do que a soma das partes perceber é "dispor" um mundo. Para os propósitos do presente artigo, dois aspectos desse "fazer mundo" são relevantes: o caráter semântico do perceber e sua construção coletiva, intersubjetiva e cultural. Como já notava Merleau-Ponty (1994, p. 257): "A simples presença de um ser vivo já transforma o mundo físico, faz surgir aqui 'alimentos', ali um 'esconderijo', dá aos estímulos um sentido que eles não tinham. Com mais razão ainda a presença do homem no 
mundo animal." Não há aí qualquer possibilidade de que este mundo tecido no perceber seja neutro: é sempre envolvido em pulsões, desejos e toda sorte de intenções com que meu corpo se põe a elucidar a paisagem, atribuindo relevância a "isto" ou "aquilo", dispondo um mundo já banhado em sentido. Diremos, assim, que perceber é dispor um mundo constituído de relações dinâmicas investidas de sentido.

Entretanto, ao dispor de tal mundo, o perceber ativo do corpo situado em sua circunstância tem também caráter intersubjetivo, isto é: a percepção é amplamente normatizada pela cultura. Se, por um lado, temos perspectivas diferentes, complementares; por outro, estas se dão a partir de um mundo em comum, um acordo intersubjetivo que define, para além da base fisiológica similar, os termos daquilo que se busca no mundo.

Como bem demonstrado pela antropologia - por exemplo, em Classen (1992) e Howes (2003) - cada cultura define um modo próprio de ordenação do mundo sensível, produz seu estilo próprio de gestalt. Historicamente, nas culturas ocidentais a primazia da visão é flagrante, decisiva mesmo para certo modelo de conhecimento (CROSBY, 1997). Mas há culturas que estabelecem seu mundo coletivo sob a primazia do olfato, do tato, ou da audição, com consequências profundas no modo de relação com o espaço, o tempo, as coisas e os seres. Assim, como afirma Howes (2003, p. 258), "A sensação (...) é o domínio mais fundamental de expressão cultural, o meio através do qual todos os valores e praticas da sociedade são articulados".

\section{Gesto, a Constituição da Intersubjetividade e a Linguagem}

Afirma Merleau-Ponty: "É por meu corpo que compreendo o outro, assim como é por meu corpo que percebo "coisas". Assim, "compreendido", o gesto não está atrás dele, ele se confunde com a estrutura do mundo que o gesto desenha e que por minha conta eu retomo, ele se expõe no próprio gesto (...)" (MERLEAU-PONTY, 1994, p. 251 - grifo nosso). Perceber é, portanto, ao mesmo tempo dispor um mundo, e fazê-lo dentro dos limites da normatização coletiva da cultura. A partir daí, como se pode pensar a linguagem que diz o mundo?

Um caminho possível é entendê-la, em primeiro lugar, como um gesto, como um dos usos possíveis de meu corpo. Para MerleauPonty, o gesto é o modo como o corpo intencional, criador de mundo e de sentido, se dirige ao mundo e "dá pela primeira vez um sentido humano ao objeto". É na consumação do gesto, no performar expressivo, que se caminha para a constituição de um mundo, em direção à subjetividade partilhada. A expressão, o gesto expressivo, é 
potencialidade de meu corpo, pela qual se dirige e se realiza no mundo. Quaisquer que sejam as dimensões da minha experiência interior, é por meio deste performar no mundo que ela adquire carne: adquire o contorno do mundo, realiza-se na partilha do comum e na construção da intersubjetividade. Por meio do gesto, o mundo percebido, meu dispor mundo, sempre inacabado e sempre na produção de si mesmo, no seu incessante encenar do horizonte das minhas condutas, ganha materialidade, ganha existência no sensível, adquire uma dimensão nova de completude, "assim como o artista só tem um meio de representar-se a obra na qual trabalha: é preciso que ele a faça" (MERLEAU-PONTY, 1994, p. 246 - grifo nosso).

O gesto, expressão de uma interioridade, se configura como tal para um observador, para um outro: como bem notou Maturana (2002), é este que lhe atribui uma semântica. Assim, esse gesto, que se dá na direção do mundo disposto segundo as condições do perceber, tem três aspectos importantes: é significação de mundo - na medida em que exterioriza o sentido constituído no perceber; é tomada de posição em relação a este mundo - na medida em que o perceber é sempre incompleto, o gesto reafirma ou questiona o que se dispõe; e é partilha de mundo, na medida em que por meio do gesto se constitui a intersubjetividade (diz Vilém Flusser (1986), a respeito do "gesto que produz imagens": "imagem é visão tornada fixa e intersubjetiva").

A linguagem aparece assim como uma das possibilidades de meu corpo, em que este, bastando a si mesmo e dentro de suas possibilidades, ascende a um horizonte da linguagem que ultrapassa aquele inaugurado por outras possibilidades expressivas. Assim, a fala é gesto: possibilidade de meu corpo; e a fala é algo à parte, é um modo como meu ser se eleva para um mundo paralelo, espelho do mundo, um mundo de representações que, como diz MerleauPonty (2002), ao mesmo tempo, se escora em si mesmo e se ultrapassa. A fala é assim um gesto singular, que não pode ser simplesmente reduzido a um "gesto entre os gestos". Gostaríamos de chamar a atenção aí a dois aspectos.

Em primeiro lugar, é preciso notar que, embora maior parte dos relatos sobre a aquisição de linguagem (por exemplo, em Chomsky) privilegiem as chamadas áreas de linguagem do cérebro, a fala envolve todo o corpo. Como descreveu bem Stephen Feld (2005, p. 184):

Som, escuta, e voz, constituem um nexo corporal distinto para sensação e emoção, devido à sua coordenação complexa de cérebro, sistema nervoso, cabeça, ouvidos, peito, músculos, respiração. (...) Mais ainda, escuta e voz estão conectadas por retroalimentação auditiva e ressonância física, a experiência imediata da própria presença por meio 
da câmara de eco do peitoral e da cabeça, principalmente da própria voz.

Não se trata de afirmar que a capacidade para a linguagem não dependa em grande medida das estruturas neuronais, mas de que, como facilmente se pode notar no caso dos deficientes auditivos, por exemplo, a diferença do aparato corporal (e perceptivo) incide em diferenças radicais na linguagem.

Em segundo lugar, notamos que, no ser humano, o biológico e o cultural se entrelaçam de modo indissociável, "no sentido em que não há uma só palavra, uma só conduta que não deva algo ao ser simplesmente biológico -- e que ao mesmo tempo não se furte à simplicidade da vida animal" (MERLEAU-PONTY, 1994, p. 257). O falar, em sua condição de gesto, é um performar em que o perceber, realizando-se como significação, tomada de posição e partilha, se completa no fazer incessante de mundo. Mas ainda que a linguagem tome ao mundo percebido as suas estruturas, ela é, a um só tempo, o "excesso de nossa existência sobre o ser natural" e o gesto que recolhe esse excesso de volta, ao constituir a presença sensível do mundo linguístico e cultural, fazendo "voltar a cair no ser o que tendia para além" (MERLEAU-PONTY, 1994, p. 266-267). Assim, a fala, potência do corpo, é certamente um gesto; mas um gesto de luxo, em que o humano se eleva acima do imediato, num âmbito que não pode ser reduzido à mera circunstância biológica em que se a instancia.

\section{Motivação para o Experimento com Figuras Ambíguas}

Para verificar empiricamente o modo como se dá a alquimia em que o falado busca consagrar o percebido como sentido, realizamos um experimento cognitivo, que buscou aproximar-se do modo como uma comunidade com traços culturais bem definidos - isto é, hipoteticamente apta a perceber e significar segundo uma intenção embutida em um campo de estudos disciplinares - percebe e descreve algumas imagens ambíguas, relacionadas com tal campo de estudos.

Ao apresentar figuras ambíguas a alunos de graduação, o que se busca é verificar se os temas e conceitos que dominam os estudos em determinado campo de saber podem interferir na elucidação de situações indefinidas em termos conceituais, verificando o modo como a expressão do percebido em linguagem verbal permite consagrar um sentido de mundo cuja gênese se dá no perceber e que se consagra na sua expressão em linguagem.

A linguagem, de fato, só pode emergir quando há uma partilha de um domínio fenomênico em comum, isto é, quando dois ou mais 
indivíduos compartilham um mesmo domínio de interações. Estes indivíduos partilham um mundo em comum, coabitam um horizonte em que constituem os mesmos objetos. É somente quando se experiencia este acoplamento a um mundo em comum, no qual a percepção, constituída coletivamente, institui um domínio de objetos compartilhados, é que se poderá então, em algum momento, designar estes objetos em comum por meio de gestos, e finalmente, por meio de um gesto de linguagem. Assim, a linguagem toma, como diz Merleau-Ponty, suas estruturas à experiência compartilhada; mas, ao mesmo tempo em que nomeia os objetos em comum do mundo coletivo, estabelece um novo domínio comum de interações, um domínio de interações na linguagem, pelo qual se ultrapassa um comportamento imediato por um comportamento não apenas categorizante -- na medida em que um único termo pode descrever conjuntos de objetos -- mas um comportamento que permite a emergência de uma consciência reflexiva. Ao consagrar um domínio fenomenológico de interações, um sentido atribuído coletivamente ao mundo por uma cultura, um modo de acesso às coisas fixado na conversa e nas trocas comunicativas, a linguagem funda um novo domínio autônomo de objetos em comum, objetos de linguagem: de tal modo que o homem poderá. cada vez mais, viver na linguagem. Ao fazê-lo não apenas descobre uma potência nova, aquela da descrição da circunstância, e em consequência da reflexividade que o distingue como vivente, mas descobre que pode estabelecer relações entre os objetos de linguagem de tal modo a rebatê-las sobre o real, transformando, de modo recursivo, os próprios modos de percebê-lo.

A transformação do perceber após a aquisição da linguagem pela criança é bem conhecida (por exemplo, Vernon (1974, p. 27) ou Merleau-Ponty (1994, p. 241). A constatação de que as relações entre percepção e linguagem não são apenas na direção mundopalavra, bottom-up, mas igualmente top-down, na direção palavramundo, resulta em que, na atitude natural, "o mundo linguístico e intersubjetivo não nos espanta mais, nós não o distinguimos do próprio mundo" (MERLEAU-PONTY, 1994, p. 250). As consequências deste movimento de duplo sentido, deste feedback entre percepçãolinguagem-percepção (num loop indefinido) não são triviais. Tal processo de loop entre a percepção e a linguagem, em que já não se pode distinguir qual vem primeiro, pode ser pensado finalmente como uma espécie de limite da cultura. Se entendemos que o perceber é já produção de sentido, que a fala é o gesto de elevação que consagra o mundo percebido e rebate sobre ele de tal modo que se tornam indissociáveis - tanto quanto meu corpo é biologia e cultura -, é neste espaço que se dão as possibilidades do meu fazer mundo: a cultura é o espaço em que pode se dar o meu performar em direção ao sentido. 


\section{Método}

O experimento, aprovado pelo Comitê de Ética na Pesquisa da Faculdade de Medicina de Botucatu (Protocolo CEP 3347-2009), foi realizado em sala de aula, em quatro turmas de cursos de graduação do Instituto de Biociências de Botucatu-UNESP, tendo como sujeitos os alunos das disciplinas Filosofia e Metodologia da Ciência, cursos de Física Médica e Ciências Biomédicas; Fundamentos de Filosofia e Ciências Humanas, cursos de Ciências Biológicas, Bacharelado e Licenciatura, totalizando um universo de 120 sujeitos. A participação dos alunos foi voluntária e anônima. Aqueles que se dispuseram a participar assinaram o Termo de Consentimento.

O objetivo principal do experimento foi descrever como a percepção de figuras ambíguas se expressa em termos da linguagem verbal. Um segundo objetivo foi de natureza didática, pois procuramos mostrar aos alunos, na prática, de que maneira é realizada uma pesquisa em Ciências Humanas, inclusive nos aspectos éticos. Os objetivos foram considerados como sendo compatíveis e complementares. Ressaltamos que esta pesquisa foi realizada em ambiente natural, ou seja, em um contexto habitual para os sujeitos (a sala de aula que frequentam diariamente), caracterizando-se, portanto, como um trabalho de campo. Como o objetivo principal é de natureza descritiva, não envolvendo explicações em termos causais, não foram realizados controles, os quais seriam necessários caso fosse testada uma hipótese explicativa. O objetivo secundário é de natureza didática, também dispensando os requisitos necessários ao teste de hipóteses.

Foram apresentadas, na sala de aula onde os alunos se encontravam para cursar as disciplinas acima, três figuras ambíguas (Figuras 2, 3 e 4) de autoria de Alfredo Pereira Jr e Maria Clara Feres Pereira. Estas haviam sido elaboradas há cerca de 30 anos, em desenho de aquarela sobre papel sulfite, sem a intenção de serem utilizadas neste contexto. As figuras foram apresentadas por meio de arquivo de formato Powerpoint, projetado em tela, durante três minutos cada uma. Após cada apresentação (sem os respectivos títulos das figuras) foi solicitado aos alunos que descrevessem por escrito o que perceberam, sendo concedidos 5 minutos para cada resposta. 


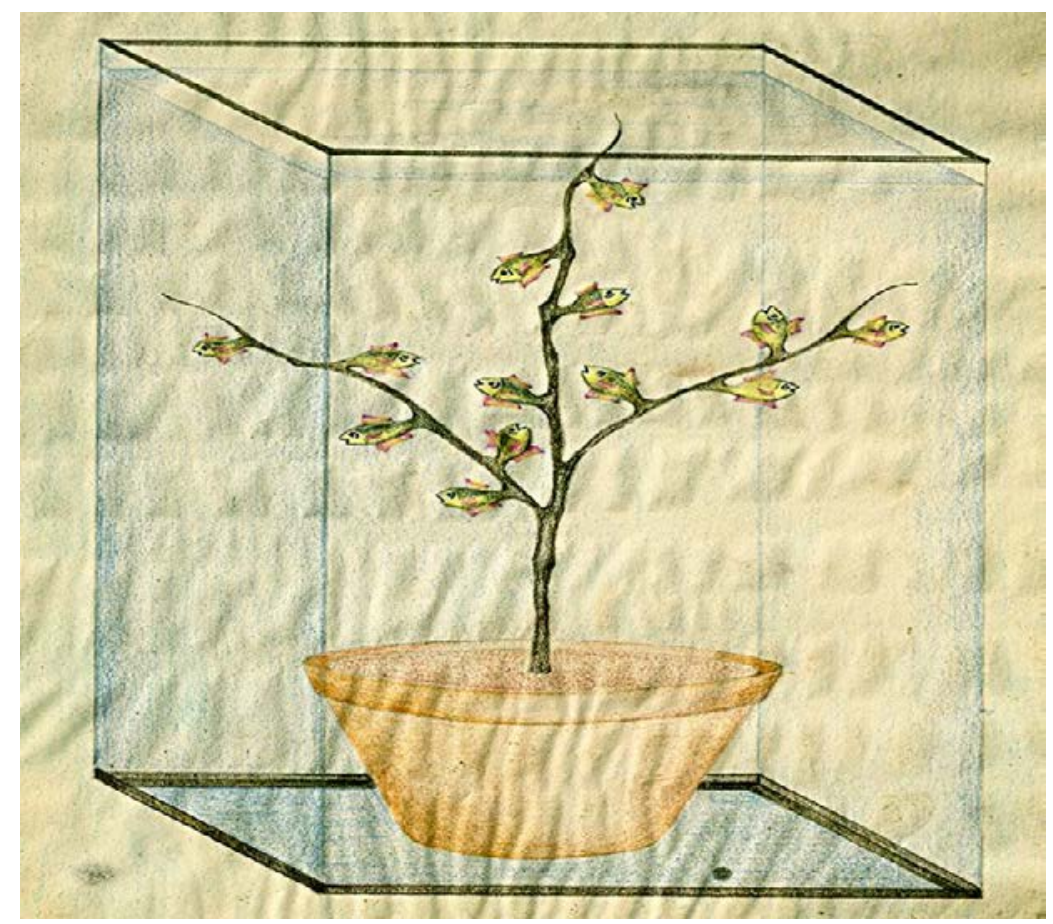

Figura 2: A Hera do Aquário

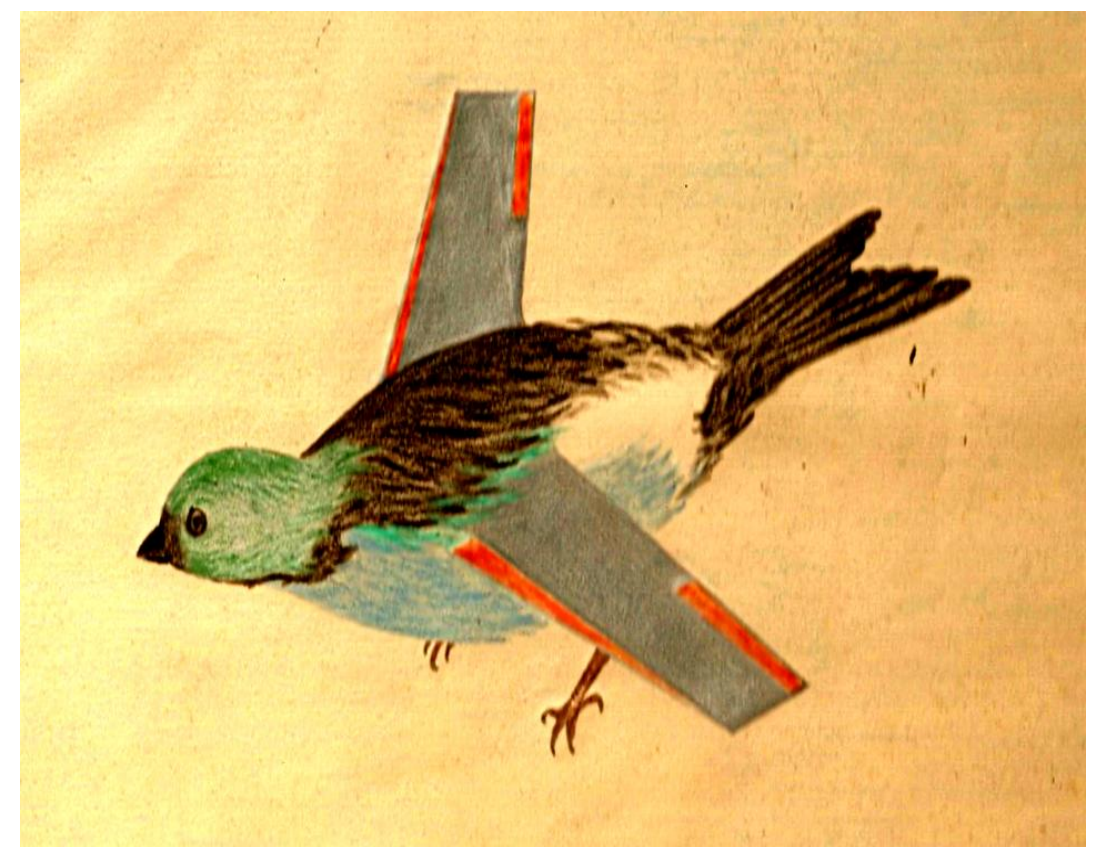

Figura 3: Um Pássaro? Um Avião? 


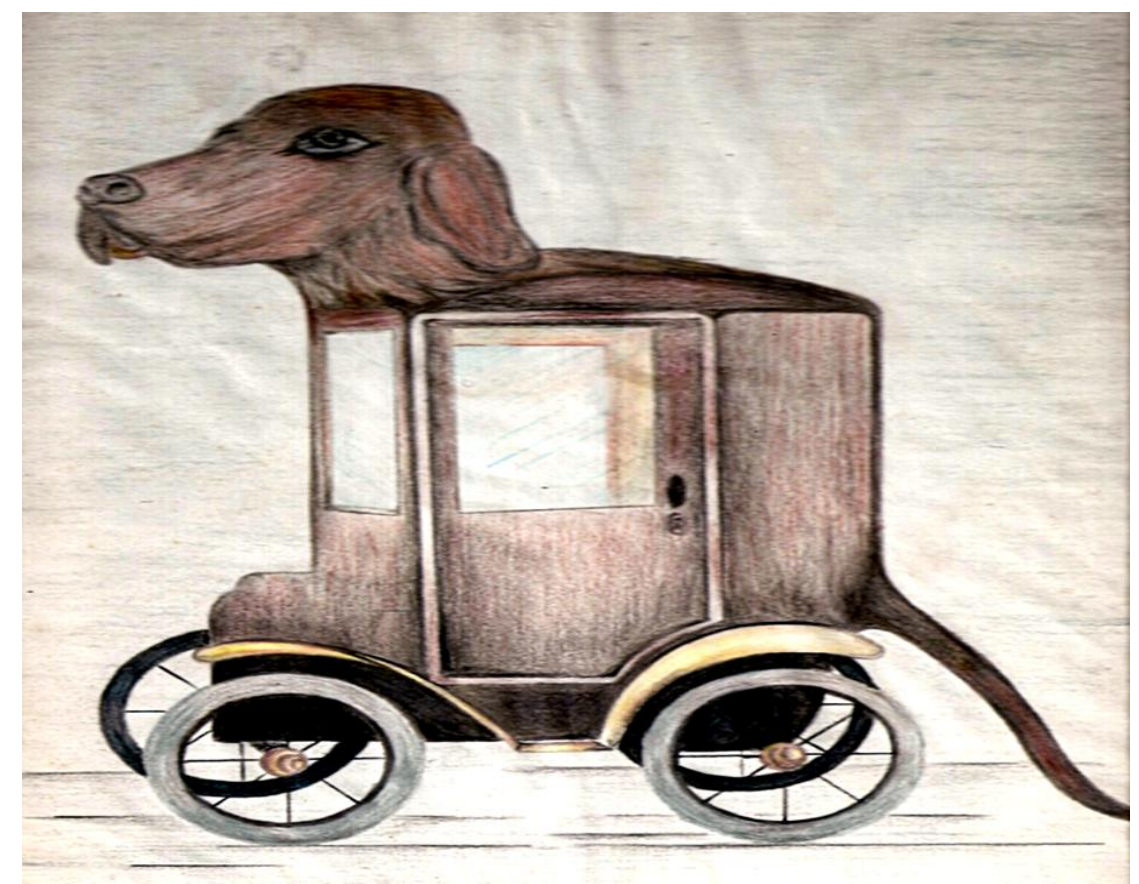

Figura 4: Dois Amigos em Um

Após tabulados os resultados, foi feita uma análise e categorização, verificando se os sujeitos utilizam apenas as categorias mais tradicionais (animal, planta, automóvel, avião) ou se aparece também a noção de formas híbridas, por exemplo a noção de transgenia para a Figura 2.

$\mathrm{Na}$ interpretação das respostas, utilizamos dois procedimentos. Inicialmente classificamos as respostas em categorias, que denotariam três estágios da evolução da cultura humana condicionantes dos modos como os sujeitos percebem as figuras apresentadas: interações com plantas e animais, interação com máquinas (automóveis e aviões), e geração de híbridos (como os seres transgênicos). Em cada resposta foi considerado o tema predominante. Por exemplo, se o sujeito descreve uma figura como sendo "um pássaro com asas de avião" a categoria predominante é "plantas e animais". Se a descreve como "um avião com formas de pássaro", a categoria dominante é "máquina"; finalmente, se a descreve como "uma mistura de pássaro e avião" a categoria dominante é "híbrido".

Em seguida, utilizamos o Discurso do Sujeito Coletivo (DSC), uma metodologia qualitativa, para organizar os dados obtidos. Com o DSC é possível a apreensão dos significados dos depoimentos os quais, como nos ensina a linguística e a semiótica, só são resgatáveis na modalidade do discurso. Através dessa metodologia, segundo Lefèvre e Lefèvre (2005), pode-se resgatar as representações sociais presentes nos discursos de uma coletividade sobre um conjunto de fenômenos, mantendo a singularidade de cada discurso. Sendo 
assim, o DSC caracteriza-se pela reconstrução, a partir de respostas individuais, de quantos discursos síntese forem necessários para expressar uma representação social (LEFÈVRE; LEFĖVRE, 2005). O discurso coletivo é feito pela união de trechos das respostas obtidas pelos alunos. Esses trechos são denominados por expressões-chave, fragmentos selecionados das respostas que melhor descrevem 0 conteúdo dentro de uma determinada ideia central; aquelas constituem a própria substância ou matéria prima da opinião, ou seja, o detalhamento do conteúdo e dos argumentos da opinião coletiva. As ideias centrais são fórmulas sintéticas que descrevem o(s) sentido(s) semelhantes ou complementares, presentes nos depoimentos de cada resposta. Assim a elaboração de um DSC ocorre pela reunião das expressões chaves nos depoimentos, que possuem ideias centrais de sentido semelhante ou complementar. O DSC é sempre na primeira pessoa do singular, justamente para sugerir uma pessoa coletiva falando como se fosse um sujeito individual de discurso.

\section{Resultados}

Na Tabela 1, são reproduzidas as porcentagens de respostas para cada tema. Um total de 86 alunos escreveram voluntariamente a respeito de suas percepções das imagens visualizadas, sendo que alguns não fizeram descrições de uma ou outra figura. Foram contadas apenas as respostas nas quais um dos temas destacados (natureza, híbrido, máquina ou metáfora) pudesse ser claramente discernido.

\section{Tabela 1}

\begin{tabular}{|l|l|l|l|l|}
\hline $\begin{array}{l}\text { Distribuição de } \\
\text { Percepçóes por } \\
\text { Temas }\end{array}$ & $\begin{array}{l}\text { Percepção de } \\
\text { Natureza } \\
\text { Máquina }\end{array}$ & $\begin{array}{l}\text { Percepcão de } \\
\text { de } \\
\text { Híbrido }\end{array}$ & $\begin{array}{l}\text { Percepção } \\
\text { de Metáfora }\end{array}$ \\
\hline $\begin{array}{l}\text { Figura 2 - A Hera do } \\
\text { Aquário }\end{array}$ & $62,666 \%$ & $13,333 \%$ & $20,000 \%$ & $4,000 \%$ \\
\hline $\begin{array}{l}\text { Figura 3 - Um Pássaro? Um } \\
\text { Avião? }\end{array}$ & $86,666 \%$ & $2,666 \%$ & $8,000 \%$ & $2,666 \%$ \\
\hline $\begin{array}{l}\text { Figura 4 - Dois Amigos em } \\
\text { Um }\end{array}$ & $21,951 \%$ & $48,780 \%$ & $24,390 \%$ & $4,878 \%$ \\
\hline
\end{tabular}

Tabela 1: Porcentagens das respostas obtidas, nas quais houve percepção de um dos temas listados na fileira superior. Para a figura 2, 'A Hera de Aquário', os dois primeiros temas foram "Percepção de Vegetal" e "Percepção de Animal", ao invés de "Percepção de Natureza" e "Percepção de Máquina". 
A figura 2 foi relatada por um total de 75 alunos; destes, 47 $(62,6667 \%)$ tiveram dessa imagem a percepção de um vegetal; 10 alunos $(13,3333 \%)$ tiveram a percepção de um animal; 15 alunos $(20,0000 \%)$ entenderam a imagem como a junção das duas coisas, ou seja, como um híbrido; e apenas três alunos $(4,0000 \%)$ tiveram da imagem uma percepção metafórica.

Quanto à figura 3, 75 alunos transcreveram suas percepções; grande parte deles - 65 alunos $(86,6667 \%)$ - relataram a imagem como algo da natureza; apenas dois alunos $(2,6667 \%)$ visualizaram a ideia de uma máquina (ou fruto da tecnologia); seis alunos $(8,0000 \%$ ) tiveram a percepção de um híbrido; e dois alunos $(2,6667 \%)$ relataram uma visão metafórica.

Para a figura 4, obtivemos o relato de 82 alunos; 18 deles (21.9512\%) visualizaram algo da natureza; a maioria dos alunos, um total de 40 (48.7805\%), perceberam uma máquina; grande parte dos alunos, 20 deles $(24.3902 \%)$ disseram se tratar da junção das duas coisas; e quatro alunos $(4.8780 \%)$ identificaram uma metáfora.

Além dessa simples análise quantitativa, interpretamos as respostas do ponto de vista qualitativo, utilizando o método DSC.

\section{Figura 2}

I deia Central 1: Percepção de um vegetal

DSC: “Há uma figura de uma árvore imersa dentro de um aquário. Ela está plantada em um vaso marrom, a planta não possui flores e nem frutos. Ela é acinzentada e se trifurca em galhos mais finos. Em uma dessas ramificações existem cinco peixes pendurados como folhas; nas outras duas ramificações existem peixes pendurados da mesma maneira, mas são quatro peixes em cada galho. Estes peixes estão nos locais onde geralmente vemos as folhas. Ao mesmo tempo em que a árvore parece seca, os peixes parecem secos dentro da caixa."

I deia Central 2: Percepção de um animal

DSC: "A figura é uma imagem de um aquário de vidro com água. Peixes estão dispostos como se fossem as folhas da planta, imitando inclusive as cores de folhas. Uma tentativa de árvore filogenética de peixes de uma forma bem abstrata. Sinto má impressão em vê-los presos pela cauda à planta."

I deia Central 3: Percepção de um híbrido.

DSC: “Essa não é uma árvore comum. Ela tem peixes no lugar de folhas; pode-se dizer que é uma árvore de peixes. Um bonsai de peixinhos amarelos e vermelhos dentro de um aquário cheio de água. Houve uma mistura de ambientes e seres vivos. Uma representação possível é de que plantas e peixes, assim como todo meio ambiente estão de algum modo interligados; o vaso da imagem representaria a origem da vida e os galhos e ramos seriam as diferenciações entre os seres vivos." 
I deia Central 4: percepção metafórica.

DSC: “Peixe é dependente de água; peixes em um aquário estão presos por pedaços de vidros os quais limitam sua liberdade de locomoção; presos à árvore, esses peixes estão mais presos ainda, ou seja, essa figura é a representação da total falta de liberdade. Estes peixes parecem tentar nadar, mas não conseguem, pois estão fixos ao tronco dessa planta. Nota-se um tom de desespero em seus rostos"

\section{Figura 3}

I deia Central 1: Percepção de natureza.

DSC: “Um passarinho gordo e colorido com asas de avião. As pernas do pássaro estão esticadas como para imitar as rodas de um avião. A cabeça do pássaro é verde, a região do peito é azul claro, mas atrás há uma mancha branca. As asas são cinzas com detalhes em laranja, apenas uma das patas é totalmente visível. A cauda do pássaro é em " V". O fundo da figura é bege claro. O animal está aparentemente em vôo; dá a idéia de um possível pouso."

I deia Central 2: Percepção de máquina.

DSC: "Na verdade o avião do homem imita o padrão das estruturas de um pássaro. O homem manipulando o vôo".

I deia Central 3: Percepção como híbrido.

DSC: “Um pássaro cujas asas foram substituídas por asas de avião, ou um avião cuja todas as peças, menos as asas foram substituídas por um pássaro sem asas. É uma analogia entre o avião e o pássaro, ambos aptos a voar. Assim estabelece uma conexão entre animais e o homem. Este, através de sua capacidade desenvolveu aviões. O céu contempla ao mesmo tempo a beleza natural e uma grande tecnologia."

I deia Central 4: Percepção metafórica.

DSC: “Liberdade. Ganhar o céu, soltar a imaginação e deixar o pensamento vagar pelo infinito horizonte do pôr do sol. As aves chegam a lugares que os homens são alcançam de avião. Para mim é a inspiração humana da aviação; o sonho de voar como um pássaro realizado."

\section{Figura 4}

I deia Central 1: Percepção de natureza.

DSC: "A imagem é a de um cachorro, mas que tem um corpo em forma de carro. A cabeça do cachorro se encontra em cima do teto do carro e seu rabo como uma continuação da parte de trás do veículo. Suas patas são quatro rodas, por serem de um carro antigo, parecem rodas de bicicleta; o carro possui uma janela de cada lado; o cachorro é marrom e parece estar sobre uma rua dando a idéia de movimento; o restante do fundo é branco e preto. Essa figura lembra muito um brinquedo de crianças pequenas, em que as patas dos animais eram rodinhas e 
amarrava-se uma corda em um brinquedo para ser puxado. A idéia que passa é que é um animal sendo utilizado para realizar transportes para os seres humanos (atividades ou lazer). Também vejo nesta imagem o cão como se fosse um guia, que me remete a idéia da importância do animal doméstico na vida de alguns seres humanos. Nesse caso podemos relacionar a imagem ao fato de pessoas cegas utilizarem o cão como guia, peça fundamental na vida destes."

I deia Central 2: Percepção como máquina.

DSC: “A imagem ilustra um carro antigo, de estrutura semelhante a de um coche fechado. Ele é marrom e a porta parece uma porta convencional de casa, por ter maçaneta e lugar para fechadura. O carro tem em seu teto um grande cachorro: a cabeça, a parte do pescoço e as costas dele são anormalmente grandes. Na traseira do carro, descendo do fim da carroceria até o chão existe um rabo de cachorro. É uma daquelas charretes que levavam a alta sociedade de um lado para o outro antigamente. Essa imagem pode significar familiaridade, pois os cachorros tendem a ser os melhores amigos do homem; demonstrando ser uma charrete interessante de se passear ou comprar. Assim como pode significar a fidelidade de um cachorro transposta num carro; seria o automóvel que nunca te deixaria na mão: econômico, resistente e seguro".

I deia Central 3: Percepção como híbrido.

DSC: "Junção de algo do mundo natural com a máquina. Fusão de partes de um cachorro e partes de um carro; o primeiro como guia (já que está representado pela cabeça e o rabo) e o segundo como suporte e locomoção (rodas e estrutura). Portanto, a imagem ilustra um cachorro - carro. Mais do que isso a imagem mostra o quanto o cachorro e o carro se relacionam com os homens."

I deia Central 4: Percepção metafórica.

DSC: “Pode-se interpretar de uma forma estética alguém que goste muito de cães e quis reproduzi-lo em um objeto de utilidade para ele. Também dá-se a idéia de consumismo; o homem transforma um objeto em algo precioso, querido, no seu melhor amigo, como se o carro fosse um animal de estimação devido ao cuidado que o homem tem com ele. Assim, vejo como o tempo passa e a humanidade se torna escrava das novas tecnologias; como são consumidas pelo consumismo em nossa época, em que a quantidade de veículos de transporte é tão grande que já tomaram o lugar dos cães."

\section{Comentários finais}

Os resultados quantitativos mostram a incidência de uma visão naturalista, comum no contexto dos cursos da área biológica, e eventualmente uma intencionalidade tecnológica, possivelmente deflagrada pela percepção da Figura 4 (interpretada por $48,780 \%$ dos alunos como sendo uma máquina).

A percepção da Figura 2 em termos de um híbrido se aproximaria da visão tecnológica, pois na contemporaneidade vivenciada pelos sujeitos a tecnologia tem avançado na manipulação das formas de 
vida. Aquilo que para os antigos aparecia como monstruosidade (a quimera), é hoje visto como alternativa tecnológica, como no caso das plantas e animais transgênicos. Entretanto, verificamos que apenas uma minoria de $20 \%$ dos alunos atribuíram este significado à figura 2.

Além destas duas visões, naturalista e tecnológica, encontramos também as respostas que chamamos de metafóricas, pois expressam a capacidade de imaginação e criação que acontecem no processo perceptivo. Este tipo de visão foi minoritária nos resultados quantitativos (correspondendo a $4 \%$ das respostas para a figura 2 , $2,666 \%$ das respostas para a figura 3 e $4,878 \%$ das respostas para a figura 4). Uma possível explicação seria que os alunos estão habituados a perceber o mundo de tal forma que sua imaginação seja limitada pelas regras do método científico (diferentemente, por exemplo, de alunos de cursos de Artes).

$\mathrm{Na}$ análise qualitativa utilizando $\mathrm{O}$ DSC, verificamos que se manifestou uma riqueza de possibilidades interpretativas, indicando como a linguagem e seus condicionantes culturais possibilitam um desdobrar de nuances perceptivas a respeito das figuras ambíguas. Como se trata de um estudo descritivo, não procuramos explicar tais resultados, mas apenas ilustrar como a concepção Merleau-Pontyana da percepção e da linguagem nos permite entender a variedade de significações atribuídas a este tipo de estímulo, em um contexto habitual para os sujeitos estudados.

\section{Referências}

BASBAUM, S. Consciousness and culture: The point of experience and the meaning of the world we inhabit. Revista Eletrônica I nformação e Cognição, Marília, v. 5, n. 1, p. 181-203, 2006.

CHOMSKY, N. Linguagem e Mente. Brasília: Editora Universidade de Brasília, 1998.

CLASSEN, C. Worlds of Sense: exploring the senses in history and across cultures. New York: Routledge, 1993.

CROSBY, A. W. A mensuração da realidade - a quantificação e a sociedade ocidental - 1250-1600. São Paulo: Editora Unesp, 1999.

ENGEL, A.; KÖNIG, P. Paradigm shifts in the neurobiology of perception. In: RATSCH, V.; RICHTER, M.; STAMATESCU. Intelligence and artificial intelligence: an interdisciplinary debate. Berlin: Springer, 1998.

FELD, S. Places sensed, sensed places. In: HOWES, D. Empire of the senses - the sensual culture reader. Oxford: Berg, 2005. FLUSSER, V. Texto/imagem enquanto dinâmica do Ocidente. Cadernos Rioarte, Rio de Janeiro, n. 5, 1986. 
HOWES, D. Sensual Relations - engaging the senses in culture and social theory. Ann Arbor: Michigan University Press, 1993. LEFĖVRE, F.; LEFÈVRE, A. M. O Discurso do Sujeito Coletivo. Caxias do Sul: EDUCS, 2005.

LEFĖVRE, F.; LEFĖVRE, A. M. Depoimentos e Discursos. Brasília: Distrito Federal, 2005.

MARKS, L. E. The Unity of the Senses. New York: Academic Press, 1978.

MATURANA, H. Ontologia da Realidade. Belo Horizonte: Editora da UFMG, 2002.

MATURANA, $H$; VARELA, F. A árvore do conhecimento - as bases biológicas do entendimento humano. Campinas: Editorial Psy, 1995.

MERLEAU-PONTY, M. Fenomenologia da Percepção. São Paulo: Martins Fontes, 1994.

MERLEAU-PONTY, M. A prosa do Mundo. São Paulo: Cosac \& Naify, 2002.

NOE, A. Action in perception. Cambridge: MIT Press, 2004.

VERNON, M. D. Percepção e Experiência. São Paulo: Perspectiva, 1974.

\author{
Endereço para correspondência \\ Alfredo Pereira J únior \\ Instituto de Biociências, Universidade Estadual Paulista (UNESP) - Botucatu. \\ Distrito de Rubião J unior S/N, Botucatu, SP \\ Endereço eletrônico: apj@ibb.unesp.br \\ Lujani Aparecida Camilo \\ Universidade Estadual Paulista (UNESP), Faculdade de Medicina de Botucatu, \\ Pós-graduação em Saúde Coletiva \\ Distrito de Rubião J unior S/N, Botucatu, SP \\ Endereço eletrônico: lujaniapc@gmail.com \\ Rafael Fernandes Barros \\ Universidade Estadual Paulista (UNESP), Faculdade de Medicina de Botucatu, \\ Pós-graduação em Saúde Coletiva \\ Distrito de Rubião Junior S/N, Botucatu, SP \\ Endereço eletrônico: rafaelfbarros@uol.com.br \\ Rafael Peres dos Santos \\ Universidade Estadual Paulista (UNESP), Faculdade de Medicina de Botucatu, \\ Hospital das Clínicas \\ Distrito de Rubião J unior S/N, Botucatu, SP \\ Endereço eletrônico: rafalmir@gmail.com \\ Sérgio Roclaw Basbaum \\ Faculdade de Ciências Exatas e Tecnologia, Pontifícia Universidade Católica -- São \\ Paulo \\ Rua Marquês de Paranaguá, 111, São Paulo, SP \\ Endereço eletrônico: sergiobasbaum@pucsp.br
}

Recebido em: 19/11/2010

Estud. pesqui. psicol., Rio de Janeiro, v. 12, n. 2, p. 462-478, 2012. 
Sérgio Roclaw Basbaum, Rafael Peres dos Santos, Rafael Fernandes Barros,

Lujani Aparecida Camilo, Alfredo Pereira Júnior

Percepção e Linguagem

Reformulado em: 21/02/2011

Aceito para publicação em: 22/02/2011

Acompanhamento do processo editorial: Adriana Benevides Soares

\section{Notas}

* Professor assistente do Departamento de Computação PUC-SP.

**Graduado em Ciências Biomédicas pelo Instituto de Biociências - UNESP Campus de Botucatu.

***Graduado em Ciências Biomédicas pelo Instituto de Biociências - UNESP Campus de Botucatu.

****Graduado em Ciências Biomédicas pelo Instituto de Biociências - UNESP Campus de Botucatu.

*****Professor Adjunto do Instituto de Biociências da Universidade Estadual Paulista (UNESP) - Campus de Botucatu. 